Open Access

\title{
Transient Uncertainty Analysis in Solar Thermal System Modeling
}

\author{
Heejin Cho ${ }^{*}$ D, Aaron Smith, Rogelio Luck and Pedro J. Mago
}

* Correspondence:

cho@me.msstate.edu

Department of Mechanical

Engineering, Mississippi State

University, Mississippi State, MS

39762, USA

\begin{abstract}
Complex, dynamic, computational models are routinely used to evaluate and optimize the design and performance of solar thermal systems. As models become more complex, performing uncertainty analysis on such models can be quite challenging and computationally expensive. This paper presents an effective approach to quantify uncertainties associated with transient simulation results from a dynamic solar thermal energy system model with uncertain parameters. The proposed method utilizes the concept of impulse response and convolution process to estimate the sensitivities to time-varying external inputs. Using this method, the number of simulations required to propagate uncertainties through dynamic models can be significantly reduced. An example is presented throughout the paper to demonstrate the procedure of the proposed uncertainty analysis approach.
\end{abstract}

Keywords: Solar thermal, Dynamic model, Uncertainty, Sensitivity

\section{Introduction}

A computational model of a complex energy system is often required to evaluate and optimize the design and performance of the actual system, e.g., [1-4]. When systems and their models are complex (i.e., containing large numbers of parameters and requiring extensive computational time to converge under time-varying condition), assuring the reliability and accuracy of models becomes very challenging and a methodical and efficient way to estimate uncertainty is necessary. The quantification of uncertainty is an essential feature in the verification and validation $(\mathrm{V} \& \mathrm{~V})$ procedures to validate simulation results against experimental measurements [5]. In addition, a long-term (e.g., a whole year) evaluation of system performance, which is often a necessary feature when the system performance depends on weather conditions or varying operational circumstances, makes uncertainty analysis even more difficult.

A variety of computational models have been developed to evaluate and optimize the design and performance of solar thermal systems [6-12]. Those models have been implemented in many engineering software tools such as TRNSYS [13], EnergyPlus [14], and Modelica [15]. While many studies have been done in this area, relatively few have considered the effects of uncertainty on the reliability of the results and conclusions. $\mathrm{Xu}$ et al. [11] presented a TRNSYS based optimization study of a solar thermal system with consideration of uncertainty. The Monte-Carlo method was used to analyze the uncertainty in the system. However, the study only considered a very limited number of

(c) The Author(s). 2017 Open Access This article is distributed under the terms of the Creative Commons Attribution 4.0 International License (http://creativecommons.org/licenses/by/4.0/), which permits unrestricted use, distribution, and reproduction in any medium, provided you give appropriate credit to the original author(s) and the source, provide a link to the Creative Commons license, and indicate if changes were made. 
uncertain parameters. Additionally, the simulation included dynamic elements, but since the study only considered cumulative effects the model was simplified to a regression that eliminated the dynamics. Dominguez-Munoz et al. [12] also presented an uncertainty analysis of the design of a solar thermal system that was based on a dynamic model. The study considered many uncertain parameters and inputs using the Monte-Carlo method for uncertainty propagation. A powerful method for design optimization under uncertainty was presented. However, this study only evaluated cumulative effects of the uncertainty over long periods of time rather than presenting the propagation of uncertainty for each time step.

This paper presents an approach to quantify uncertainties associated with transient simulation results from a dynamic solar thermal energy system model with uncertain input parameters. The uncertainty in the simulation result is composed of contributions from the errors due to modeling assumptions and approximations, numerical solution of the equations, and simulation inputs [5]. This study primarily focuses on determining uncertainties due to simulation inputs including model parameters, initial conditions, and transient external inputs. The sensitivity (i.e., partial derivative) to each model parameter and initial condition at each time step can be determined by perturbing each of the arguments at a nominal value. The sensitivity to the time-varying external inputs can be determined in a similar manner by calculating sensitivities at each time step. However, this numerical procedure can be greatly simplified using the principle of linearity and superposition. The proposed method utilizes the impulse response and the convolution process to estimate the sensitivities to time-varying external inputs. Finally, the total uncertainties on the final result due to the simulation input parameters are estimated based on the sensitivities and systematic/random uncertainties [5].

\section{Model Description}

\section{Description of the System}

A schematic of the solar water heating system addressed in this study is shown in Fig. 1. The system collects heat from incident solar radiation by circulating water through the collector. A water tank is incorporated to store thermal energy for future use. Because the temperature of the water in the tank will vary based on the weather conditions, this

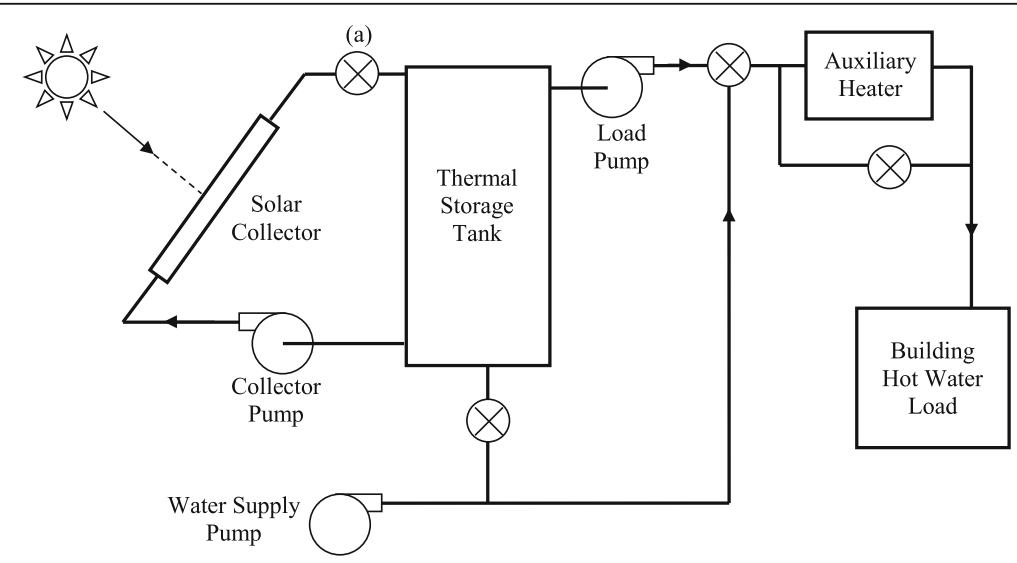

Fig. 1 Schematic of solar water heating system 
system must incorporate multiple operating modes to meet the building hot water demand. If the water temperature in the tank is greater than or equal to the desired load temperature, the water from the tank is mixed with water from the city supply to provide the desired temperature. In this case, the auxiliary heater is bypassed. However, if the water from the tank is too low, the auxiliary heater is used to provide the additional heat.

\section{Energy Conservation of the Storage Tank}

The storage tank temperature can be modeled using energy conservation. Assuming that the tank is well mixed, a single capacitance can be used to model the energy stored in the tank as

$$
\rho V c_{\mathrm{p}} \frac{d T_{\mathrm{st}}}{d t}=q_{\mathrm{c}}-q_{\mathrm{LD}}-q_{\mathrm{LS}}
$$

where $\rho$ and $c_{\mathrm{p}}$ are the density and specific heat of water, $V$ is the storage volume of the tank, $T_{\mathrm{st}}$ is the average temperature of the water in the tank, $q_{\mathrm{c}}$ is the energy collected in the solar collector, $q_{\mathrm{LD}}$ is the energy used to meet the building hot water load, and $q_{\mathrm{LS}}$ is the energy lost through the tank walls to the ambient environment. The energy transferred to the water in the solar collector can be determined by a heat transfer balance on the collector between energy absorbed from solar radiation and energy lost by convection to the ambient environment. The effective energy transferred to the water has been defined by Duffie and Beckman [10] as

$$
q_{c}=\left[A_{\mathrm{c}} F_{\mathrm{R}}\left(I_{\mathrm{T}} \mathrm{\tau} \alpha-U_{\mathrm{c}}\left(T_{\mathrm{st}}-T_{\mathrm{amb}}\right)\right)\right] \Phi_{\mathrm{Va}}
$$

where $A_{\mathrm{c}}$ is the collector area, $F_{\mathrm{R}}$ is the heat removal factor, $I_{\mathrm{T}}$ is the total solar radiation incident on the collector surface, $\tau \alpha$ is the transmittance-absorptance product for the collector glazing, and $U_{\mathrm{c}}$ is the loss coefficient for the collector. The variable $\Phi_{\mathrm{Va}}$ is a Heaviside step function that represents the opening and closing of the valve in energy collection loop (i.e., location (a) in Fig. 1) to maximize energy collection. This step function is equal to one (i.e., the valve at (a) is open) when the heat transfer to the water in the collector is positive and equal to zero (i.e., the valve at (a) is closed) otherwise. The incident radiation on the collector surface can be determined from standard radiation measurements such as the diffuse and direct radiation on the horizontal. However, the relationship between these standard measurements and the radiation incident on the collector surface varies with the position of the sun in the sky. Therefore, the ("Definition of Radiation Incident on Collector Surface" section) gives the equations for angles of the sun as a function of time and location.

The convective heat loss through the tank walls can be defined as

$$
q_{\mathrm{LS}}=U_{\mathrm{st}} A_{\mathrm{st}}\left(T_{\mathrm{st}}-T_{\mathrm{amb}}\right),
$$

where $U_{\mathrm{st}}$ is the loss coefficient for the storage tank, $A_{\mathrm{st}}$ is the exposed surface area of the storage tank, and $T_{\mathrm{amb}}$ is the ambient temperature.

The energy used to meet the building hot water load would be dependent on the user needs. For the case study addressed in this work, a hot water load profile for a small multi-family house is assumed based on a hot water usage schedule from the residential 
prototype building models developed by the Pacific Northwest National Laboratory. ${ }^{1} \mathrm{~A}$ typical load for a day is illustrated in Fig. 2.

\section{Definition of Radiation Incident on Collector Surface}

This section gives a derivation of the equation used to relate standard radiation measurements to the radiation incident on the collector surface. The derivation follows the work by Duffie and Beckman [10] and is included here for completeness. The total radiative flux incident on the collector surface is a function of diffuse, direct, and ground reflected radiation components and can be defined as

$$
I_{\mathrm{T}}=I_{\mathrm{s}, \text { beam }}+I_{\mathrm{s}, \text { diff }}+I_{\mathrm{s}, \mathrm{GR}},
$$

where $I_{\mathrm{s} \text {,beam }}$ is the component on the collector surface due to beam radiation, $I_{\mathrm{s} \text {,diff }}$ is the component due to diffuse radiation, and $I_{\mathrm{s}, \mathrm{GR}}$ is the component due to ground reflected radiation. Radiation measurements are typically reported as beam and diffuse radiation on a horizontal surface. Therefore, these components must be adjusted for the slope of the collector surface with respect to horizontal and the position of the sun. The diffuse radiation on a surface tilted from the horizontal at angle, $\beta$, is defined as

$$
I_{\mathrm{s}, \mathrm{diff}}=I_{\mathrm{d}}\left(\frac{1+\cos (\beta)}{2}\right)
$$

where $I_{\mathrm{d}}$ is the diffuse irradiation on a horizontal surface. The beam radiation on the tilted surface can be defined as

$$
I_{\mathrm{s}, \text { beam }}=I_{\mathrm{b}} \cos (\theta),
$$

where $I_{\mathrm{b}}$ is the beam radiation on a horizontal surface and $\theta$ is the angle of incidence (i.e., the angle between the direct sun beam and the normal to the collector surface). The radiation on the collector surface from ground reflected radiation can be defined as

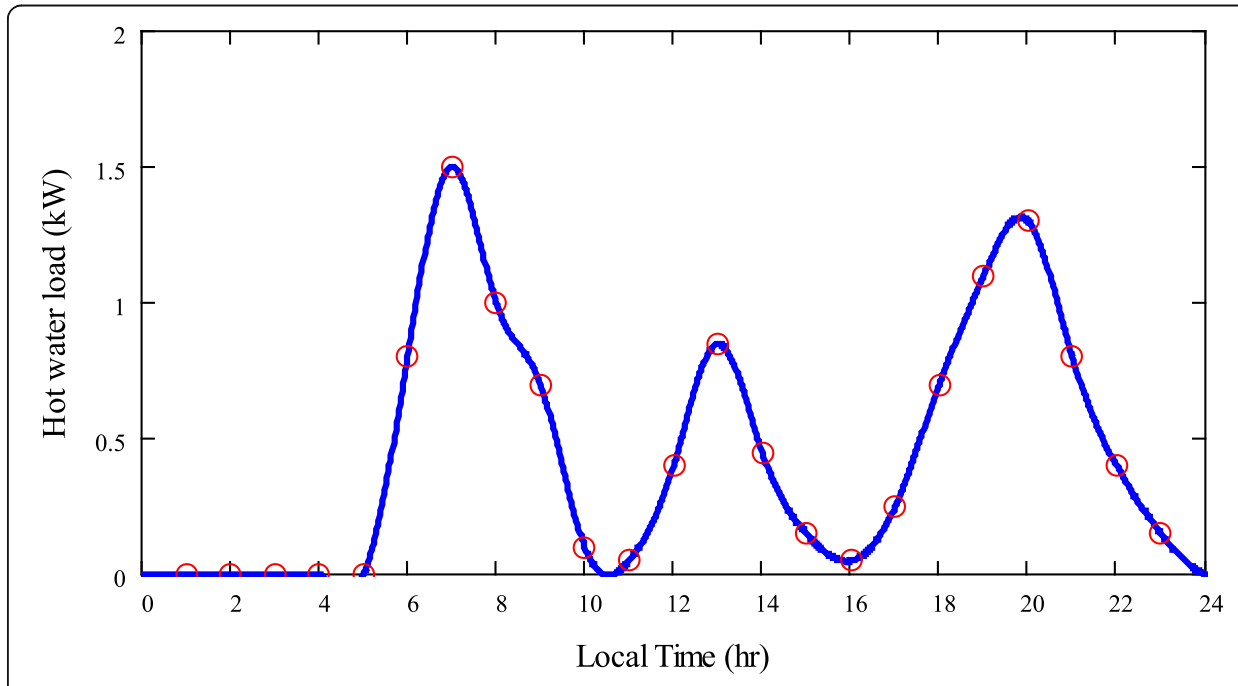

Fig. 2 Building hot water load for a typical day 


$$
I_{\mathrm{s}, \mathrm{GR}}=\left(I_{\mathrm{b}} \cos \left(\theta_{\mathrm{z}}\right)+I_{\mathrm{d}}\right)\left(\frac{1-\cos (\beta)}{2}\right) \rho_{\mathrm{g}}
$$

where $\rho_{\mathrm{g}}$ is the reflectivity of the ground and $\theta_{\mathrm{z}}$ is the solar zenith angle (i.e., the incidence angle for a horizontal surface). The solar zenith angle is illustrated in Fig. 3a. For this simulation, the ground reflectance is assumed to be 0.2 , which is the commonly used value in the building energy simulations [16].

The angle of incidence is defined as

$$
\cos (\theta)=\sin \left(\theta_{\mathrm{z}}\right) \cos \left(\gamma_{s}-\gamma\right) \sin (\beta)+\cos \left(\theta_{\mathrm{z}}\right) \cos (\beta),
$$

where $\gamma_{s}$ is the solar azimuth angle (i.e., the angle between south and the projection of the beam onto the horizontal, see Fig. 3b) and $\gamma$ is the tilted surface azimuth angle. The solar zenith angle and the solar azimuth angle can be found using Eqs. (9) and (10), respectively, as

$$
\begin{aligned}
& \cos \left(\theta_{\mathrm{z}}\right)=\sin (\phi) \sin \left(\delta_{s}\right)+\cos (\phi) \cos \left(\delta_{s}\right) \cos \left(\omega_{s}\right) \\
& \gamma_{s}=\operatorname{sign}\left(\omega_{s}\right)\left\|\arccos \left[\frac{\cos \left(\theta_{\mathrm{z}}\right) \sin (\phi)-\sin \left(\delta_{s}\right)}{\sin \left(\theta_{\mathrm{z}}\right) \cos (\phi)}\right]\right\|,
\end{aligned}
$$

where $\phi$ is the latitude of the site, $\delta_{s}$ is the solar declination, and $\omega_{s}$ is the hour angle. The function sign returns the sign of the argument. Therefore, if $\omega_{s}$ is positive, $\operatorname{sign}\left(\omega_{s}\right)=1$; otherwise, $\operatorname{sign}\left(\omega_{s}\right)=-1$. The solar declination refers to the angle of the sun relative to the equatorial plane of the earth. The solar declination for a given hour in the year can be obtained as

$$
\delta_{\mathrm{s}}=23.45^{\circ} \sin \left[360^{\circ} \frac{\left(\frac{h_{\mathrm{solar}}}{24}+284\right)}{365}\right],
$$

where $h_{\text {solar }}$ corresponds to the hour in the year in terms of solar time. Solar time only corresponds to local time if the site is located along the standard meridian for the local time zone. Otherwise, the time must be corrected proportional to the amount the location varies from the standard meridian. The time correction can be defined as

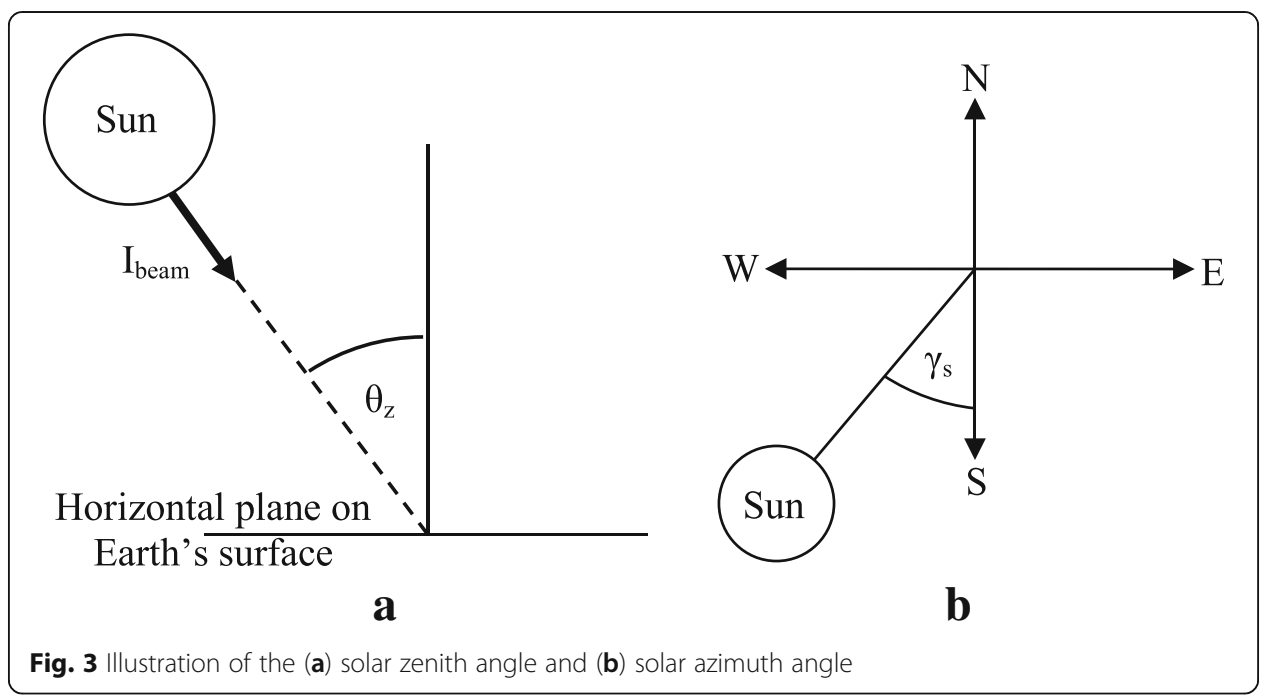




$$
h_{\mathrm{solar}}=h_{\mathrm{local}}+\left(\frac{1}{60}\right)\left[4\left(L_{\mathrm{st}}-L_{\mathrm{local}}\right)+E\right]
$$

where $h_{\text {local }}$ is the hour in local time, $h_{\text {solar }}$ is the hour in solar time, $L_{\text {local }}$ is the longitude at the site location, $L_{\mathrm{st}}$ is the longitude of the standard meridian for the time zone, and $E$ is a parameter of time correction that can be determined from the following empirical relations [17]:

$$
E=229.2\left(\begin{array}{c}
0.000075+0.001868 \cos \left(\left(\frac{h_{\text {local }}}{24}-1\right) \frac{360}{365}\right)-0.032077 \sin \left(\left(\frac{h_{\text {local }}}{24}-1\right) \frac{360}{365}\right) \\
-0.014615 \cos \left(2\left(\frac{h_{\text {local }}}{24}-1\right) \frac{360}{365}\right)-0.04089 \sin \left(2\left(\frac{h_{\text {local }}}{24}-1\right) \frac{360}{365}\right)
\end{array}\right) .
$$

Finally, the hour angle in Eqs. (9) and (10) denotes the angular displacement of the sun east or west of the local meridian due to rotation of the earth. The earth rotates at $15^{\circ} / \mathrm{h}$. The hour angle is defined to be zero at solar noon, negative in the morning, and positive in the afternoon. Therefore, for a given day, the hour angle can be defined as

$$
\omega_{s}=15^{\circ}\left(h_{\text {solar }}-12\right) \text {. }
$$

\section{Uncertainty Analysis}

\section{Nominal Tank Solution}

In this section, an example case of a flat plate solar thermal system located in San Diego, CA, USA, is used to illustrate the uncertainty analysis process for a day long simulation. Equation (1) is solved for the storage temperature in the tank by using a standard Runge-Kutta numerical solver. The storage tank temperature is calculated hourly. The storage tank temperature could be calculated for a variety of design conditions to determine if the design meets the requirements or could be implemented in an algorithm as part of an effort to optimize the operation method under uncertainty.

The numerical solution for Eq. (1) at each time step, $k$, can be defined as a function of the parameters and inputs to the system.

$$
\left(T_{s t}\right)_{\mathrm{k}}=F\left(P_{1}, \ldots, P_{\mathrm{N}},\left(q_{\mathrm{LD}}\right)_{1}, \ldots,\left(q_{\mathrm{LD}}\right)_{\mathrm{k}},\left(I_{\mathrm{d}}\right)_{1}, \ldots,\left(I_{\mathrm{d}}\right)_{\mathrm{k}},\left(I_{\mathrm{b}}\right)_{1}, \ldots,\left(I_{\mathrm{b}}\right)_{\mathrm{k}},\left(T_{\mathrm{amb}}\right)_{1}, \ldots,\left(T_{\mathrm{amb}}\right)_{\mathrm{k}}\right)
$$

The function, F(), in Eq. (15) is based on the model developed in the "Model Description" section above. The $P$ variables represent the $N$ parameters of the system. The parameters for the model developed above are listed in Table 1. The other variables in Eq. (15) are the inputs to the system at each time step, $k$. The inputs are the hourly building load, $q_{\mathrm{LD}}$, the diffuse radiation on the horizontal, $I_{\mathrm{d}}$, the beam radiation on the horizontal, $I_{\mathrm{b}}$, and ambient temperature, $T_{\mathrm{amb}}$. An example of the storage tank temperature for a typical day is given in Fig. 4.

Figure 5 below shows the heat transfer to water in the collector, $q_{\mathrm{c}}$, for the nominal conditions. The figure shows that positive heat transfer occurs from hours 9 through 17. Therefore, the valve will be opened at 9:00 AM and closed at 6:00 PM. At this point of the development of the uncertainty analysis procedure, it is important to point out that the valve system affects the linearity and time invariance of the system with respect to the time varying inputs. 
Table 1 Parameters used to determine the storage temperature in San Diego, CA, USA

\begin{tabular}{lll}
\hline Parameter & Nominal value & Estimated uncertainty \\
\hline Local longitude $\left(L_{\text {local }}\right)$ & $117.16(\mathrm{deg})$ & 0 \\
Location latitude $(\varphi)$ & $32.733(\mathrm{deg})$ & $10 \%$ \\
Longitude of the standard meridian for the time zone $\left(L_{\mathrm{st}}\right)$ & $120(\mathrm{deg})$ & 0 \\
Collector area $\left(A_{\mathrm{c}}\right)$ & $5\left(\mathrm{~m}^{2}\right)$ & $1 \%$ \\
Heat removal factor times the transmittance-absorptance product $\left(F_{\mathrm{R}} \mathrm{Ta}\right)$ & 0.753 & $2 \%$ \\
Heat removal factor times the collector loss coefficient $\left(F_{\mathrm{R}} U_{c}\right)$ & 3.79 & $2 \%$ \\
Reflectivity of the ground $\left(\rho_{\mathrm{g}}\right)$ & 0.2 & 0.1 \\
Collector slope $(\beta)$ & $32.733(\mathrm{deg})$ & $2^{\circ}$ \\
Collector azimuth angle $(\gamma)$ & $0(\mathrm{deg})$ & $2^{\circ}$ \\
Loss coefficient for storage tank $\left(U \mathrm{~A}_{\mathrm{st}}\right)$ & 1.7 & $1 \%$ \\
Ambient temperature $\left(T_{\mathrm{amb}}\right)$ & $25\left({ }^{\circ} \mathrm{C}\right)$ & $1{ }^{\circ} \mathrm{C}$ \\
Specific heat of water $\left(c_{\mathrm{p}}\right)$ & $4.1813(\mathrm{~kJ} / \mathrm{kg} \mathrm{K})$ & 0 \\
Density of water $(\rho)$ & $974\left(\mathrm{~kg} / \mathrm{m}^{3}\right)$ & 0.1 \\
Storage tank volume $(V)$ & $0.19\left(\mathrm{~m}^{3}\right)$ & 0 \\
\hline
\end{tabular}

\section{Sensitivities of the Tank Temperature}

The first step in the uncertainty analysis is to calculate the sensitivities of the solution variable (i.e., storage temperature) to each of the parameters and inputs. Since the solution is obtained numerically, the sensitivities are obtained numerically as well. The sensitivity of the solution to a given parameter or external input can be determined using a first-order difference. For example, the sensitivity of the storage temperature at time, $k$, to the $i$ th parameter, $P_{\mathrm{i}}$, can be defined as

$$
\left(S_{\mathrm{P}_{\mathrm{i}}}\right)_{\mathrm{k}}=\frac{F\left(\begin{array}{c}
P_{1}, \ldots, P_{\mathrm{i}}+\Delta P_{\mathrm{i}}, \ldots, P_{\mathrm{N}},\left(q_{\mathrm{LD}}\right)_{1}, \ldots,\left(q_{\mathrm{LD}}\right)_{\mathrm{k}}, \\
\left(I_{\mathrm{d}}\right)_{1}, \ldots,\left(I_{\mathrm{d}}\right)_{\mathrm{k}},\left(I_{\mathrm{b}}\right)_{1}, \ldots,\left(I_{\mathrm{b}}\right)_{\mathrm{k}},\left(T_{\mathrm{a}}\right)_{1}, \ldots,\left(T_{\mathrm{a}}\right)_{\mathrm{k}}
\end{array}\right)-\left(T_{\left.\mathrm{st}_{\mathrm{N}}\right)_{\mathrm{k}}}\right.}{\Delta \mathrm{P}_{\mathrm{i}}}
$$

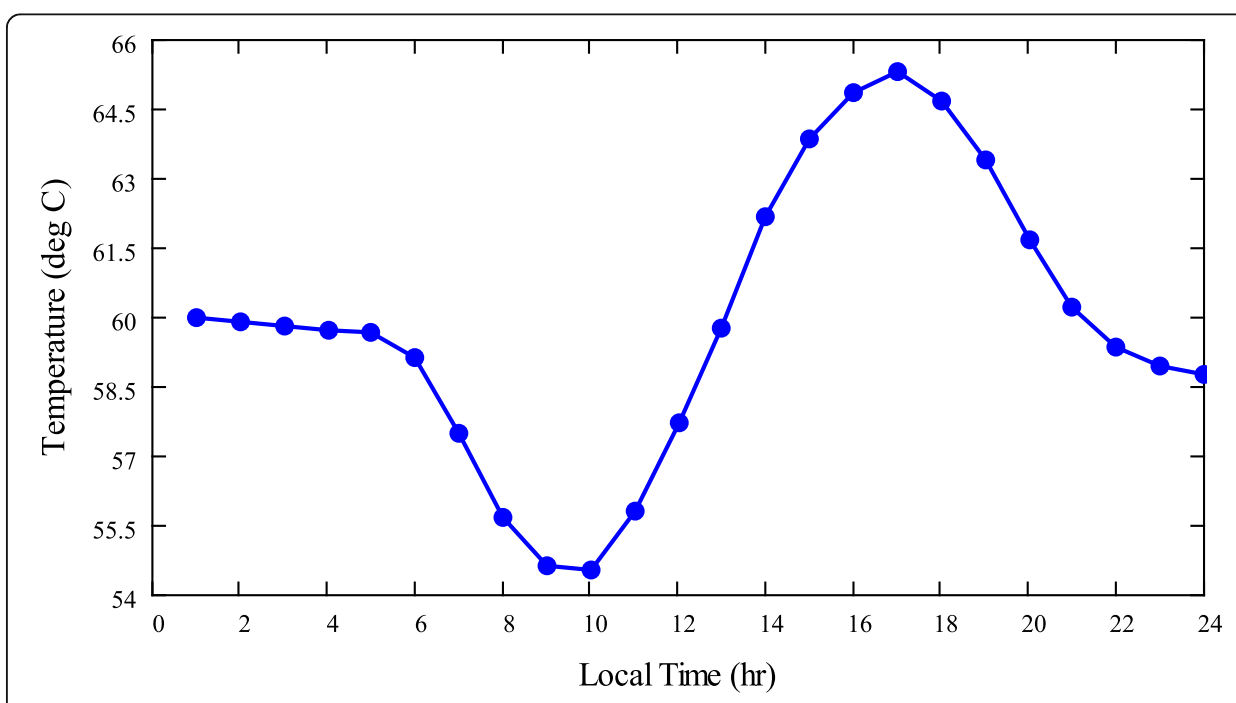

Fig. 4 Storage tank temperature (deg C) for a typical day 


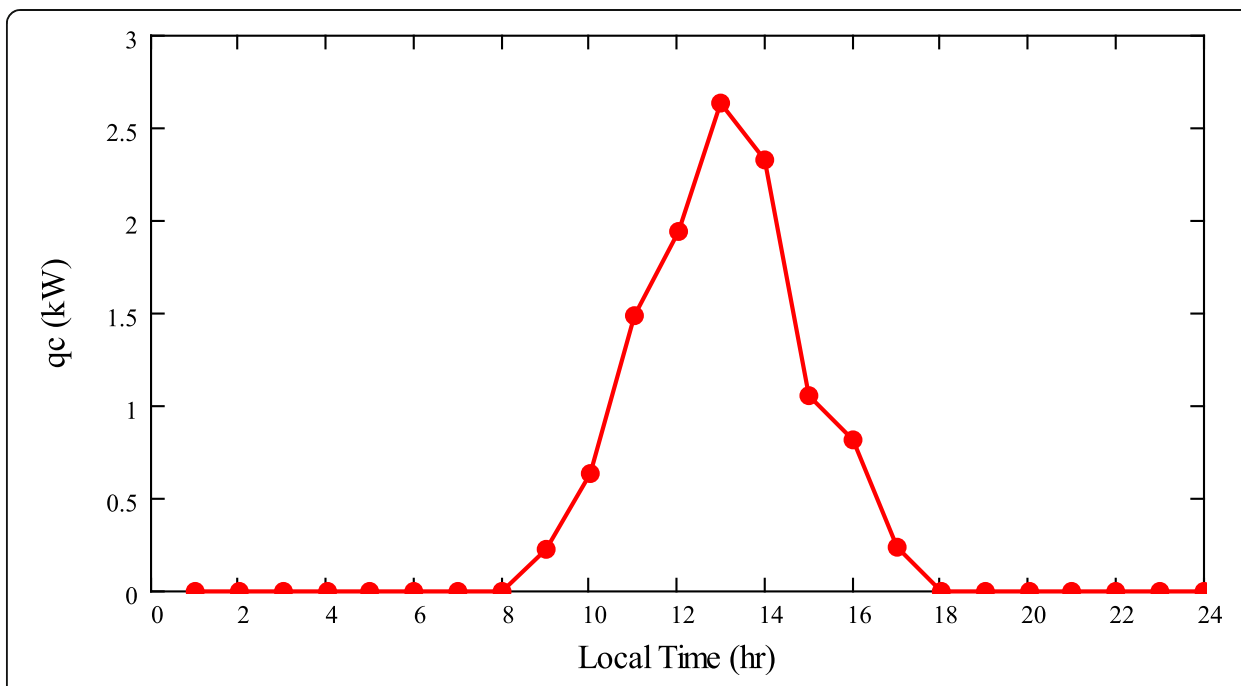

Fig. 5 Energy transferred to the water in the solar collector, $q_{c}(\mathrm{~kW})$ for a typical day

where $T_{\text {st_N }}$ represents the nominal solution which is found by simulating the system with all parameters and inputs at their nominal values. Notice that when finding the sensitivity of the solution to a given parameter, $P_{\mathrm{i}}$, only this parameter is perturbed while all other parameters and all inputs are held constant. For example, the sensitivity of the solution at time, $k$, to the collector area can be defined as

$$
\left(S_{\mathrm{A}_{\mathrm{c}}}\right)_{\mathrm{k}}=\frac{F\left(\begin{array}{c}
P_{1}, \ldots, A_{\mathrm{c}}+\Delta A_{\mathrm{c}}, \ldots, P_{\mathrm{N}},\left(q_{\mathrm{LD}}\right)_{1}, \ldots,\left(q_{\mathrm{LD}}\right)_{\mathrm{k}}, \\
\left(I_{\mathrm{d}}\right)_{1}, \ldots,\left(I_{\mathrm{d}}\right)_{\mathrm{k}},\left(I_{\mathrm{b}}\right)_{1}, \ldots,\left(I_{\mathrm{b}}\right)_{\mathrm{k}},\left(T_{\mathrm{a}}\right)_{1}, \ldots,\left(T_{\mathrm{a}}\right)_{\mathrm{k}}
\end{array}\right)-\left(T_{\left.\mathrm{st}_{\mathrm{N}}\right)_{\mathrm{k}}}\right.}{\Delta A_{c}} .
$$

An example of this sensitivity is shown in Fig. 6. This same process can be used to find the sensitivity of the solution to each parameter.

The same approach could be used for finding the sensitivities of the solution to the time varying inputs. The sensitivity of the solution at time, $k$, must be calculated for

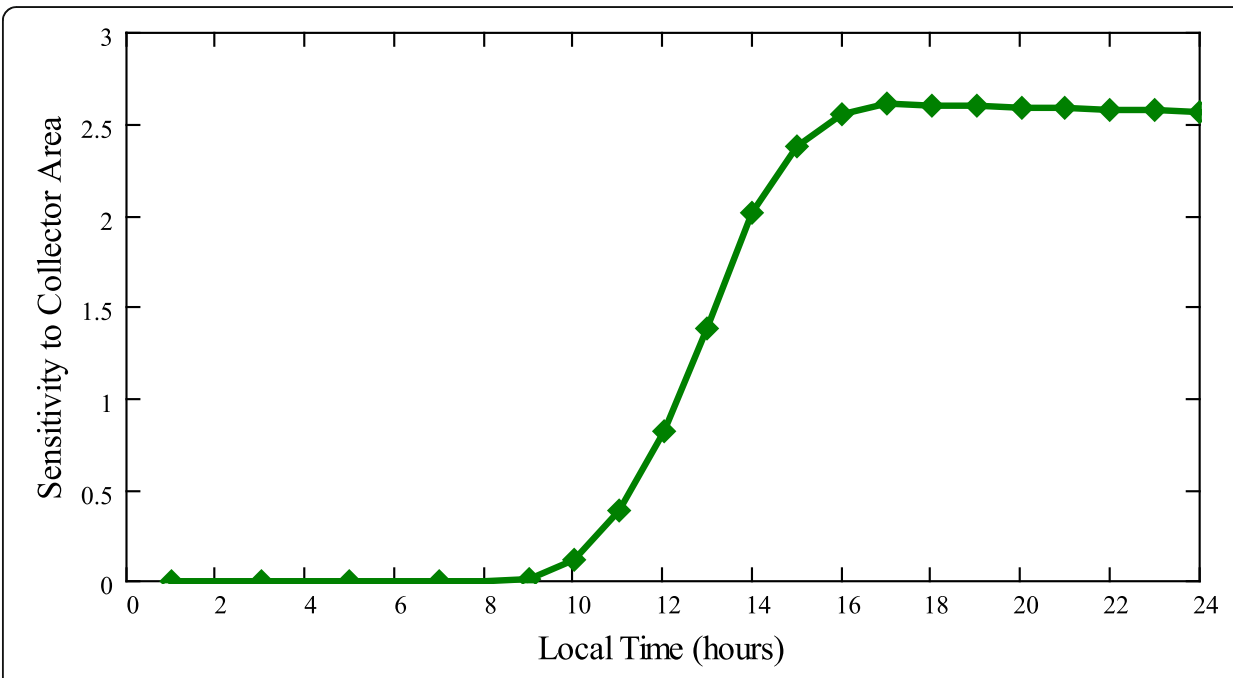

Fig. 6 Sensitivity of storage tank temperature to the collector area (units ${ }^{\circ} \mathrm{C} / \mathrm{m}^{2}$ ) 
the entire history of the time varying inputs as shown in the following equations. Note: The index $j$ is used to indicate the time that the input perturbation occurred.

$$
\begin{aligned}
\left(S_{\left(q_{\mathrm{LD}}\right)_{\mathrm{j}}}\right)_{\mathrm{k}} & =\frac{F\left(\begin{array}{c}
P_{1}, \ldots, P_{\mathrm{N}},\left(q_{\mathrm{LD}}\right)_{1}, \ldots,\left[\left(q_{\mathrm{LD}}\right)_{j}+\left(\Delta q_{\mathrm{LD}}\right)_{\mathrm{j}}\right], \ldots,\left(q_{\mathrm{LD}}\right)_{\mathrm{k}}, \\
\left(I_{\mathrm{d}}\right)_{1}, \ldots \ldots,\left(I_{\mathrm{d}}\right)_{\mathrm{k}},\left(I_{\mathrm{b}}\right)_{1}, \ldots,\left(I_{\mathrm{b}}\right)_{\mathrm{k}},\left(T_{\mathrm{a}}\right)_{1}, \ldots,\left(T_{\mathrm{a}}\right)_{\mathrm{k}}
\end{array}\right)-\left(T_{\left.\mathrm{st}_{\mathrm{N}}\right)_{\mathrm{k}}}\right.}{\left(\Delta q_{\mathrm{LD}}\right)_{\mathrm{j}}} \\
\left(S_{\left(T_{\mathrm{a}}\right)_{\mathrm{j}}}\right)_{\mathrm{k}} & =\frac{F\left(\begin{array}{c}
P_{1}, \ldots, P_{\mathrm{N}},\left(q_{\mathrm{LD}}\right)_{1}, \ldots,\left(q_{\mathrm{LD}}\right)_{\mathrm{k}}, \\
\left(I_{\mathrm{d}}\right)_{1}, \ldots,\left(I_{\mathrm{d}}\right)_{\mathrm{k}},\left(I_{\mathrm{b}}\right)_{1}, \ldots,\left(I_{\mathrm{b}}\right)_{\mathrm{k}},\left(T_{\mathrm{a}}\right)_{1}, \ldots,\left[\left(T_{\mathrm{a}}\right)_{\mathrm{j}}+\left(\Delta T_{\mathrm{a}}\right)_{\mathrm{j}}\right], \ldots,\left(T_{\mathrm{a}}\right)_{\mathrm{k}}
\end{array}\right)-\left(T_{\left.\mathrm{st}_{\mathrm{N}}\right)_{\mathrm{k}}}\right.}{\left(\Delta T_{\mathrm{a}}\right)_{\mathrm{j}}} \\
\left(S_{\left(I_{\mathrm{d}}\right)_{\mathrm{j}}}\right)_{\mathrm{k}}= & \frac{F\left(\begin{array}{c}
\left(I_{\mathrm{d}}\right)_{1}, \ldots,\left[\left(I_{\mathrm{d}}\right)_{\mathrm{j}}+\left(\Delta I_{\mathrm{d}}\right)_{\mathrm{j}}\right], \ldots,\left(I_{\mathrm{d}}\right)_{\mathrm{k}},\left(I_{\mathrm{b}}\right)_{1}, \ldots,\left(I_{\mathrm{b}}\right)_{\mathrm{k}},\left(T_{\mathrm{a}}\right)_{1}, \ldots,\left(T_{\mathrm{a}}\right)_{\mathrm{k}}
\end{array}\right)-\left(T_{\left.\mathrm{st}_{\mathrm{N}}\right)_{\mathrm{k}}}\right.}{\left(\Delta I_{\mathrm{d}}\right)_{\mathrm{j}}} \\
\left(S_{\left(I_{\mathrm{b}}\right)_{\mathrm{j}}}\right)_{\mathrm{k}}= & \frac{F\left(\begin{array}{c}
P_{1}, \ldots, P_{\mathrm{N}},\left(q_{\mathrm{L}}\right)_{1}, \ldots,\left(q_{\mathrm{LD}}\right)_{\mathrm{k}}, \\
\left(I_{\mathrm{d}}\right)_{1}, \ldots,\left(I_{\mathrm{d}}\right)_{\mathrm{k}},\left(I_{\mathrm{b}}\right)_{1}, \ldots,\left[\left(I_{\mathrm{b}}\right)_{\mathrm{j}}+\left(\Delta I_{\mathrm{b}}\right)_{\mathrm{j}}\right], \ldots,\left(I_{\mathrm{b}}\right)_{\mathrm{k}},\left(T_{\mathrm{a}}\right)_{1}, \ldots,\left(T_{\mathrm{a}}\right)_{\mathrm{k}}
\end{array}\right)-\left(T_{\left.\mathrm{st}_{\mathrm{N}}\right)_{\mathrm{k}}}\right.}{\left(\Delta I_{\mathrm{b}}\right)_{\mathrm{j}}}
\end{aligned}
$$

However, this approach would require a large number of numerical simulations. For instance, for a given time step $k$, the sensitivity must be determined for the current input as well as for the entire history of inputs. This would require $k$ additional simulations for each time varying input. In this model, there are four time varying inputs. Therefore, for a single day simulation (i.e., 24 time steps), it would take 96 simulations to calculate the sensitivities for the inputs alone. This would become especially cumbersome if there was a need for multiple day simulations. An alternative approach is taken in this work.

Assuming a linear time invariant system, the principle of superposition can be used to greatly reduce the number of simulations required. In this case, discrete convolution (i.e., a discretized version of Duhamel's integral) can be used to determine the response of the storage temperature to small changes in the input loads. Then, the impulse response can be found for each load. This impulse response can simply be multiplied by the load perturbation magnitude and shifted to the time of the load to determine the response to all perturbations. It follows that only one additional simulation will be required for each time varying input. That eliminates 92 simulations. In general using the principle of convolution reduces the number of simulations by $I^{*} N-I$, where $N$ is the number of time steps, and $I$ represents the number of inputs (i.e., four in this case). For a 1-week simulation, this method would eliminate the need for 668 numerical ODE simulations. For a 1-year simulation, this method would eliminate 35,036 simulations, requiring only four simulations for calculating the sensitivities to the inputs.

The previous discussion assumes that the model is linear and time-invariant. However, the model developed in this work has fairly strong nonlinearities due to changes in the valve states. To address this issue, the simulation was split into three zones: before collector valve is open, during collector operation, after collector valve is closed. For the ambient temperature and hot water load, a simulation is required for 
each of the three zones, while the diffuse and beam radiation only affect the solution during the time when the collector is being used.

At zone transitions, the uncertainties from the previous zone are interpreted as an uncertainty in the initial temperature for the next zone. This requires additional simulations for each zone transition and for each time-varying input that is effective leading up to the zone transition. This leads to six additional simulations for a single day simulation.

The diffuse radiation only affects the model simulation when the collector valve is open. For the case studied, the valve is open from 9:00 AM to 6:00 PM. As discussed above, finding the sensitivity of the solution to this input would require running a simulation for each time step in this range. The impulse response is found by running a simulation in which the input is perturbed in a single time step in a single variable. For example, the impulse response for a perturbation of the diffuse radiation load at $j=9$ can be determined as

$$
h_{\left(\left(I_{\mathrm{d}}\right)_{9}\right)_{\mathrm{k}}}=\frac{F\left(\begin{array}{c}
P_{1}, \ldots, P_{\mathrm{N}},\left(q_{\mathrm{LD}}\right)_{1}, \ldots,\left(q_{\mathrm{LD}}\right)_{\mathrm{k}}, \\
\left.\left(I_{\mathrm{d}}\right)_{1}, \ldots,\left(I_{\mathrm{d}}\right)_{9}+\Delta \mathrm{I}_{\mathrm{d}}, \ldots,\left(I_{\mathrm{d}}\right)_{\mathrm{k}},\left(I_{\mathrm{b}}\right)_{1}, \ldots,\left(I_{\mathrm{b}}\right)_{\mathrm{k}},\left(T_{\mathrm{a}}\right)_{1}, \ldots,\left(T_{\mathrm{a}}\right)_{\mathrm{k}}\right)-\left(T_{\mathrm{st}}\right)_{\mathrm{k}}
\end{array}\right.}{\Delta \mathrm{I}_{\mathrm{d}}} .
$$

Using the same approach for perturbations at later time steps gave almost identical impulse responses for times before closing of the collector valve (at 6:00 PM). Figure 7 shows a comparison of the impulse responses for three different perturbation times. Note that the impulse responses for later perturbation times are shifted to the left for comparison. The fact that the impulse responses are the same at different times shows the time invariance of the model with respect to diffuse radiation inputs during the time when the valve is open. This indicates that a single impulse response can be used to represent the sensitivities of the solution to diffuse radiation inputs at all remaining times when the collector valve is open. For this simulation the impulse response at 9:00 AM is used as

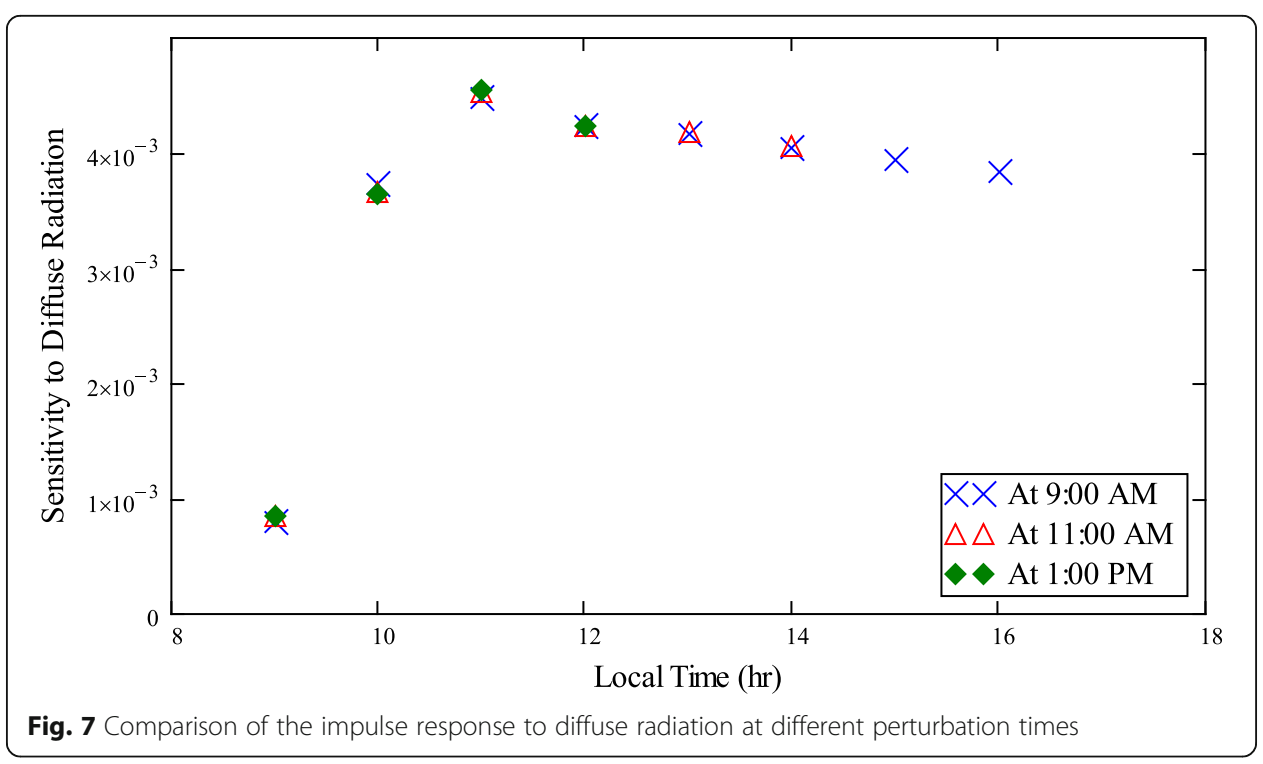




$$
\left(S_{I_{\mathrm{d}}}\right)_{\mathrm{k}}=h_{\left(\left(I_{\mathrm{d}}\right)_{9}\right)_{\mathrm{k}}} \text {. }
$$

While the diffuse radiation input does not affect the model after the valve is closed, the uncertainty of the input diffuse radiation does contribute to the uncertainty in the storage temperature after the valve is closed. However, the sensitivity of the solution to diffuse radiation is very nonlinear for times after the valve is closed. Figure 8 shows the sensitivity for various perturbation amplitudes within the expected range of the diffuse radiation uncertainty. Notice the drastic nonlinearity after the valve is closed. This same trend was found in each of the four time-varying inputs. This nonlinearity makes the truncated Taylor series method inaccurate. To overcome this difficulty, new simulations are started at the time when the collector valve is closed. The uncertainty in the tank temperature at the time when the collector valve is closed (6:00 PM or hour number 18) but obtained assuming that the collector valve is open and will be used as the uncertainty in the initial tank temperature for new "closed-valve" simulations starting at this time. Therefore, the initial condition uncertainty will capture the effect of the uncertainty in the time-varying inputs in previous time steps on the uncertainty in the solution after the collector valve is closed.

Next, the sensitivity of the solution to beam radiation will be defined. The sensitivity of the solution to beam radiation was found to be time variant. This time variance results from the fact that the contribution from the beam radiation on the collector surface is dependent on the angle between the sun and the surface as shown in Eqs. (2), (4), (6), and (7). This angle is a function of time. The chain rule can be invoked to remove the time variance shown in the sensitivity of the solution to the beam radiation as follows:

$$
\frac{\partial T_{\mathrm{st}}}{\partial I_{\mathrm{b}}}=\frac{\partial T_{\mathrm{st}}}{\partial q_{\mathrm{c}}} \frac{\partial q_{\mathrm{c}}}{\partial I_{\mathrm{b}}}
$$

The first term represents the sensitivity of the tank temperature to a change in heat transfer from the collector. The second term represents the sensitivity of the heat

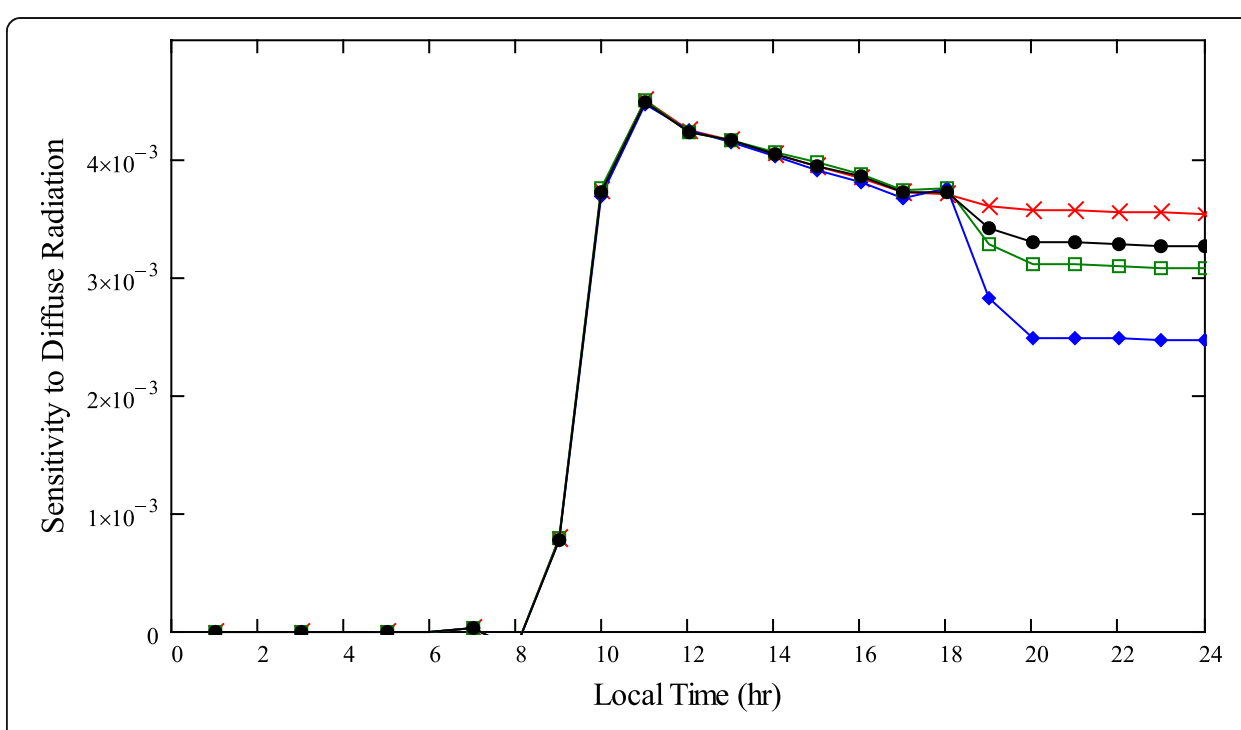

Fig. 8 Sensitivities of diffuse radiation input after the value is closed for various perturbation amplitudes 
transfer in the collector to changes in the beam radiation. This can be found by taking the derivative of (2) with respect to $I_{\mathrm{b}}$.

$$
\frac{d q_{c}}{d I_{b}}=A_{\mathrm{c}} F_{\mathrm{R}}\left[\cos (\theta)+\cos \left(\theta_{\mathrm{z}}\right)\left(\frac{1-\cos (\beta)}{2}\right) \rho_{\mathrm{g}}\right]
$$

\section{Total Uncertainty of the Tank Temperature}

Once the sensitivities are available, the total uncertainty of the storage temperature in the tank can be determined by following the procedures described in the ASME test uncertainty [18] and the ISO guide [19] to yield

$$
U_{T_{\mathrm{st}}}, \mathrm{k}^{2}=\sum_{i=1}^{N}\left(\left(S_{P_{\mathrm{i}}}\right)_{\mathrm{k}} U_{P_{\mathrm{i}, \mathrm{k}}}\right)^{2}+U_{q \mathrm{LD}, \mathrm{k}}^{2}+U_{I \mathrm{~d}, \mathrm{k}}^{2}+U_{I \mathrm{~b}, \mathrm{k}}^{2}+U_{T \mathrm{a}, \mathrm{k}}^{2},
$$

where $U_{\mathrm{P}_{\mathrm{i}, \mathrm{k}}}$ are the estimated uncertainties of the parameter $P_{\mathrm{i}}$, the list of parameters including the respective uncertainties is given in Table 1. In general, the uncertainties are estimated based on many factors such as expected measurement errors in experimental variables (obtained from instrument manufacturers), approximation errors in model parameters, conceptual errors in model equations, and engineering judgment. Additional information for estimating uncertainties can be found in references [18-20]. The nominal values of model parameters used in the present uncertainty analysis and their estimated uncertainties are listed in Table 1. Nominal values in this table refer to the model parameter values assuming zero uncertainty. The total uncertainties for the hourly building load, $q_{\mathrm{LD}}$, the diffuse radiation on the horizontal, $I_{\mathrm{d}}$, the beam radiation on the horizontal, $I_{\mathrm{b}}$, and ambient temperature, $T_{\mathrm{a}}$, can be determined using their sensitivities at time $k$ and estimated uncertainties as defined below

$$
\begin{aligned}
& U_{q \mathrm{LD}, \mathrm{k}}^{2}=\left[\sum_{j=1}^{k}\left(S_{q \mathrm{Ld}_{\mathrm{k}-\mathrm{j}}}\right)\right]^{2} U_{q \mathrm{Ld}_{\mathrm{s}}}{ }^{2}+\sum_{j=1}^{k}\left(S_{q \mathrm{Ld}_{\mathrm{j}-\mathrm{k}}}\right)^{2} U_{\mathrm{qLd}_{\mathrm{R}}}{ }^{2} \\
& U_{\mathrm{Id}, \mathrm{k}}^{2}=\left(\left(S_{\mathrm{b}}\right)_{\mathrm{k}} U_{\mathrm{b}_{\mathrm{k}}}\right)^{2}+\sum_{k=0}^{j-1}\left[S_{\mathrm{Id}_{\mathrm{j}-\mathrm{k}}}\right]^{2} U_{\mathrm{Id}_{\mathrm{R}}}{ }^{2} \\
& U_{\mathrm{Ib}, \mathrm{k}}^{2}=\left(\left(S_{\mathrm{a}}\right)_{\mathrm{k}} U_{\mathrm{a}_{\mathrm{k}}}\right)^{2}+\sum_{k=0}^{j-1}\left[S_{\mathrm{Ib}_{\mathrm{j}-\mathrm{k}}}\right]^{2} U_{\mathrm{Ib}_{\mathrm{R}}}{ }^{2} \\
& U_{\mathrm{Ta}, \mathrm{k}}^{2}=\left(\sum_{k=0}^{j-1}\left[S_{\mathrm{Ta}_{\mathrm{j}-\mathrm{k}}}\right]\right)^{2} U_{\mathrm{Tas}^{2}}{ }^{2}+\sum_{k=0}^{j-1}\left[S_{\mathrm{Ta}_{j-\mathrm{k}}}\right]^{2} U_{\mathrm{TaR}_{\mathrm{R}}}{ }^{2} .
\end{aligned}
$$

\section{Uncertainties for External Input Variables}

TMY3 data includes hourly uncertainty values for direct solar radiation and diffuse solar radiation, and these uncertainty values represent the plus or minus $95 \%$ confidence intervals for the hourly data [14]. The uncertainty for each hourly data in TMY3

Table 2 Estimated uncertainties for input variables

\begin{tabular}{llll}
\hline Input variable & Source & $\begin{array}{l}\text { Standard random } \\
\text { uncertainty }\end{array}$ & $\begin{array}{l}\text { Standard systematic } \\
\text { uncertainty }\end{array}$ \\
\hline$I_{\text {diff }}$ & Hourly values given in TMY3 & $1 \%$ of maximum daily & $10 \%$ \\
$I_{\text {beam }}$ & Hourly values given in TMY3 & $1 \%$ of maximum daily & $16 \%$ \\
$T_{\text {amb }}$ & Typical uncertainty in temperature sensors & $1{ }^{\circ} \mathrm{C}$ & $1{ }^{\circ} \mathrm{C}$ \\
$q_{\mathrm{LD}}$ & Estimation (engineering judgment) & $5 \mathrm{~W}$ & $5 \mathrm{~W}$ \\
\hline
\end{tabular}




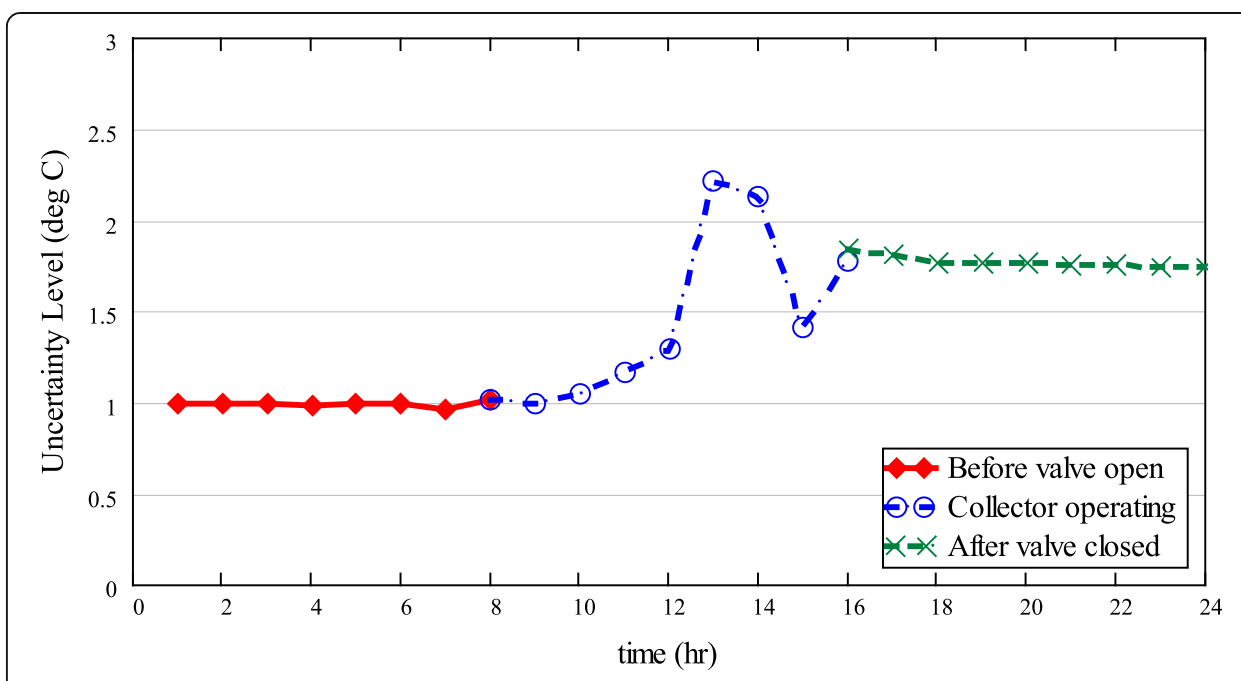

Fig. 9 Uncertainty in storage tank temperature for day simulation

data is determined by comparing predictions with measured data [15]. The uncertainty for ground reflectance $(\rho)$ is estimated to be 0.1 because many ground surfaces have the ground reflectance values between 0.1 and 0.3 based on their material [8]. The estimated uncertainties for the input variables are listed in Table 2.

\section{Results of Uncertainty Propagation}

The uncertainty analysis method presented in the "Uncertainty Analysis" section was performed for the single day simulations case study described in the "Uncertainty Analysis" section. Figure 9 summarizes the one sided 95\% uncertainty in the storage tank temperature results. Note that the graph is segmented into three sections based on the opening and closing of the collector valve. The highest uncertainty occurs when the energy transferred to the water by the solar collector is highest. Figure 10 shows

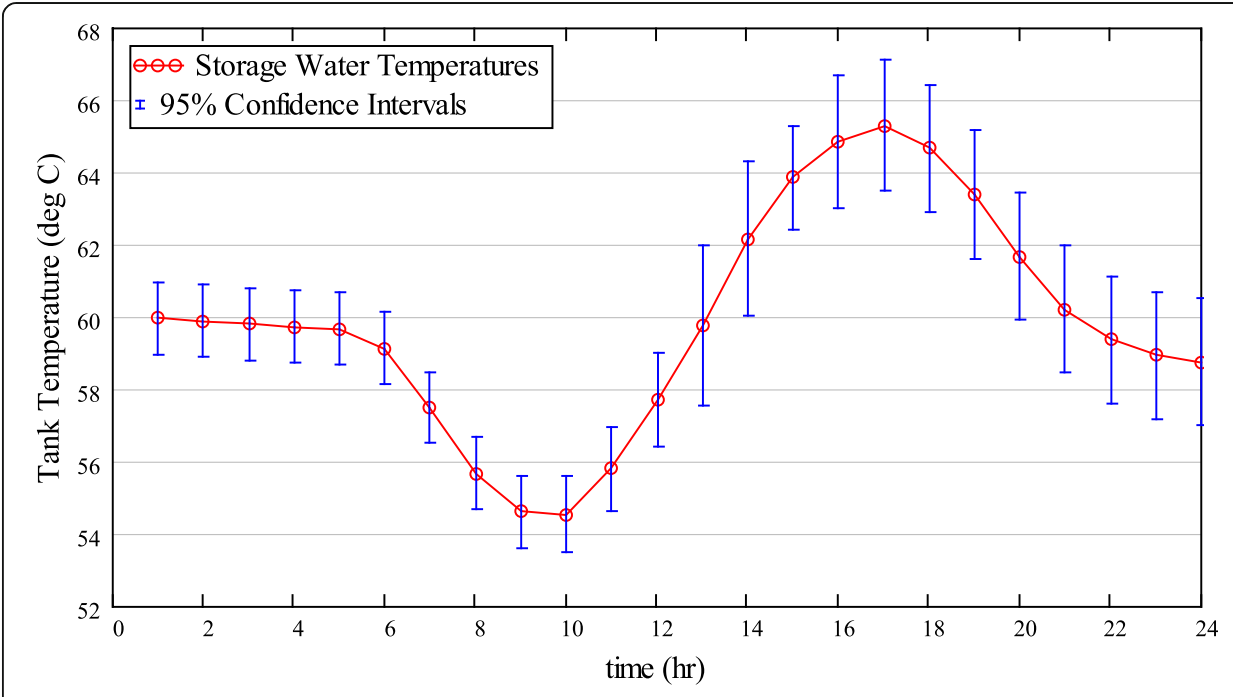

Fig. 10 Storage tank temperature with uncertainty confidence intervals 
the two-sided confidence intervals for each time step plotted over the nominal storage tank temperature solution. The results in Figs. 9 and 10 indicate that the storage temperature can vary between 1 and $2.2{ }^{\circ} \mathrm{C}$ from the nominal values obtained from the system model due to the uncertainty associated with the input parameters.

\section{Conclusion}

An approach was presented to quantify uncertainties associated with transient simulation results from a dynamic solar thermal energy system model with uncertain input parameters. The approach greatly reduced the number of simulations required by using the impulse response and convolution integral to estimate the sensitivities to time-varying external inputs. The results from the selected example indicated that the uncertainty in the time-varying temperature of the storage tank can vary as much as $\pm 2.2{ }^{\circ} \mathrm{C}$. This method can be helpful for validating models for system design and potentially for developing operation algorithms that take time varying uncertainties into account.

\section{Endnote}

${ }^{1}$ Available at https://www.energycodes.gov/development/residential/iecc_models.

Authors' Contributions

All authors have made substantial contributions to the conception, analysis, and interpretation of the data and have been involved in drafting the manuscript and revising it critically for important intellectual content. All authors read and approved the final manuscript.

\section{Competing Interests}

The authors declare that they have no competing interests.

Received: 21 September 2016 Accepted: 10 January 2017

Published online: 19 January 2017

\section{References}

1. Cho, H., Luck, R., Chamra, L.M.: Supervisory feed-forward control for real-time topping cycle CHP operation. J Energy Resour Technol 132, 012401 (2010)

2. Cho, H., Mago, P.J., Luck, R., Chamra, L.M.: Evaluation of CCHP systems performance based on operational cost, primary energy consumption, and carbon dioxide emission by utilizing an optimal operation scheme. Appl Energy 86, 2540-2549 (2009)

3. Yun, K., Cho, H., Luck, R., Mago, P.J.: Real-time combined heat and power operational strategy using a hierarchical optimization algorithm. Proceedings of the Institution of Mechanical Engineers, Part A. J Power Energy 225, 403-412 (2011)

4. Cho, H., Krishnan, S.R., Luck, R., Srinivasan, K.K.: Comprehensive uncertainty analysis of a Wiebe function-based combustion model for pilot-ignited natural gas engines. J Automobile Eng 223, 1481-1498 (2009)

5. ASME: Standard for Verification and Validation in Computational Fluid Dynamics and Heat Transfer. ASME, New York (2009)

6. Dennis Barley, C., Byron Winn, C.: Optimal sizing of solar collectors by the method of relative areas. Solar Energy 21, 279-289 (1978)

7. T. Ferhatbegovic, G. Zucker, P. Palensky, Model based predictive control for a solar-thermal system, in: AFRICON, 2011, pp. 1-6 (2011).

8. Klein, S.A., Beckman, W.A., Duffie, J.A.: A design procedure for solar heating systems. Solar Energy 18, $113-127$ (1976)

9. Kulkarni, G.N., Kedare, S.B., Bandyopadhyay, S.: Determination of design space and optimization of solar water heating systems. Solar Energy 81, 958-968 (2007)

10. Duffie, W.A. Beckman, Solar Engineering of Thermal Processes. Hoboken, John Wiley \& Sons, (2006).

11. Xu, D., Qu, M., Hang, Y., Zhau, F.: Multi-objective optimal design of a solar absorption cooling and heating system under life-cycle uncertainties. Sustainable Energy Technologies and Assessments 11, 92-105 (2015)

12. Dominguez-Munoz, F., Cejudo-Lopez, J.M., Carrillo-Andres, A., Ruivo, C.R.: Design of solar thermal systems under uncertainty. Energ Buildings 47, 474-484 (2012)

13. Beckman, W.A., Broman, L., Fiksel, A., Klein, S.A., Lindberg, E., Schuler, M., Thornton, J.: TRNSYS the most complete solar energy system modeling and simulation software. Renew Energy 5, 486-488 (1994)

14. B.T. Griffith, P.G. Ellis, N.R.E. Laboratory, Photovoltaic and Solar Thermal Modeling with the EnergyPlus Calculation Engine: Preprint, National Renewable Energy Laboratory, (2004).

15. Fontanella, G., Basciotti, D., Dubisch, F., Judex, F., Preisler, A., Hettfleisch, C., Vukovic, V., Selke, T.: Calibration and validation of a solar thermal system model in Modelica. Build Simul 5, 293-300 (2012)

16. Thevenard, D., Haddad, K.: Ground reflectivity in the context of building energy simulation. Energ Buildings 38, 972-980 (2006) 
17. M. Iqbal, An Introduction to Solar Radiation. New York, Academic Press, (1983).

18. ASME: Test Uncertainty, ASME PTC 19.1-2005. American Society of Mechanical Engineers, New York (2006)

19. ISO, Guide to the Expression of Uncertainty in Measurement: Corrected and Reprinted, 1995, International Organization for Standardization. Geneva, (1993).

20. H.W. Coleman, W.G. Steele, Experimentation and Uncertainty Analysis for Engineers. New York, Wiley, (1999).

\section{Submit your manuscript to a SpringerOpen ${ }^{\circ}$} journal and benefit from:

- Convenient online submission

- Rigorous peer review

- Immediate publication on acceptance

- Open access: articles freely available online

- High visibility within the field

- Retaining the copyright to your article

Submit your next manuscript at $>$ springeropen.com 